\title{
A new method of carboxyhaemoglobin determination
}

\author{
J. H. SANDERSON, M. F. SOTHERAN, AND J. P. STATTERSFIELD
}

From the Central Toxicology Laboratory, Imperial Chemical Industries Limited, Alderley Park, near Macclesfield, Cheshire SK10 4TJ

ABSTRACT A quick and accurate method of determining the concentration of carboxyhaemoglobin $(\mathrm{COHb})$ in blood has been developed. The method uses a dual wavelength double beam spectrophotometer in the 1st derivative mode, linked to a digital voltmeter (DVM), with the two beams set $3 \mathrm{~nm}$ apart around an isobestic point of reduced haemoglobin $\left(\mathrm{Hb}_{\text {red }}\right)$ and carboxyhaemoglobin at $579 \mathrm{~nm}$. The 1st derivative mode measures the slope, and this slope is proportional to the concentration of $\mathrm{COHb}$.

Techniques currently used to measure $\mathrm{COHb}$ levels in blood include gasometric methods, colorimetry, gas chromatography, precipitation techniques, infrared analysis and spectrophotometric methods. Not one of these methods (described in the papers listed in the Reference section) is both rapid and accurate. In an effort to combine accuracy and rapidity, attention has been concentrated on spectrophotometric methods.

\section{Theory}

The absorbance spectra of reduced haemoglobin $\left(\mathrm{Hb}_{\text {red }}\right)$ and $\mathrm{COHb}$ (Figure 1) between 600 and $500 \mathrm{~nm}$ have similar curves with three isobestic points. At the isobestic point around $579 \mathrm{~nm}$ the absorbance slope alters with concentration (Figure 2). Closer examination of absorbance curves (Figure 3 ) between 585 and $575 \mathrm{~nm}$ shows that the curves of $\mathrm{Hb}_{\text {red }}$ and $\mathrm{COHb}$ are straight lines but have different slopes. If the slope can be measured, then the concentration of $\mathrm{COHb}$ can be calculated: this is the basis of the method described here.

Figure 4 shows schematically the absorbance curve of $\mathrm{COHb}$ with the $x$ axis representing wavelength and the $y$ axis absorbance.

Absorbance $=\mathrm{C}-\mathrm{pW}$ where $\mathrm{C}=$ constant intercept of $x$ on $y$.

The slope is given by the 1st derivative

$$
=\frac{\mathrm{dA}}{\mathrm{dW}}=-\mathrm{p}
$$

Received for publication 22 April 1977 Accepted for publication 11 August 1977
Now, $\frac{\mathrm{dA}}{\mathrm{dW}} \simeq \frac{\Delta \mathrm{A}}{\Delta \mathrm{W}}$

But if $\frac{\mathrm{d}^{2} \mathrm{~A}}{\mathrm{dW}^{2}}=0$ (2nd derivative)

that is, a curve is a straight line over $\Delta \mathrm{W}$,

then, $\frac{\mathrm{dA}}{\mathrm{dW}}=\frac{\Delta \mathrm{A}}{\Delta \mathrm{W}}$

This condition holds between 576 and $580 \mathrm{~nm}$

If the $\%$ of $\mathrm{COHb} \propto \mathrm{p}$

$$
\therefore \% \mathrm{COHb}=\mathrm{Kp}=-\frac{\mathrm{KdA}}{\mathrm{dW}}=-\mathrm{K} \frac{\Delta \mathrm{A}}{\Delta \mathrm{W}}
$$

But $\Delta \mathrm{W}=$ constant

Thus, $\% \mathrm{COHb}=\mathrm{K}^{*} \Delta \mathrm{A}$

\section{Method}

Using a Perkin Elmer 356, double beam, dual wavelength spectrophotometer, 1st derivative measurement is possible. Figure 5 shows the conventional absorbance spectrum of $\mathrm{Hb}_{\text {red }}$ between 600 and $500 \mathrm{~nm}$ with its 1st derivative curve superimposed upon it. First derivative absorbance curves of various concentrations of $\mathrm{COHb}$ with the two beams set $1 \mathrm{~nm}$ apart (Figure 6), demonstrated that the greatest difference between concentrations is registered around the isobestic point at $579 \mathrm{~nm}$. When the wavelengths at which the beams are set are fixed and the spectrophotometer is attached to a digital voltmeter (DVM), a digital value for a blood 


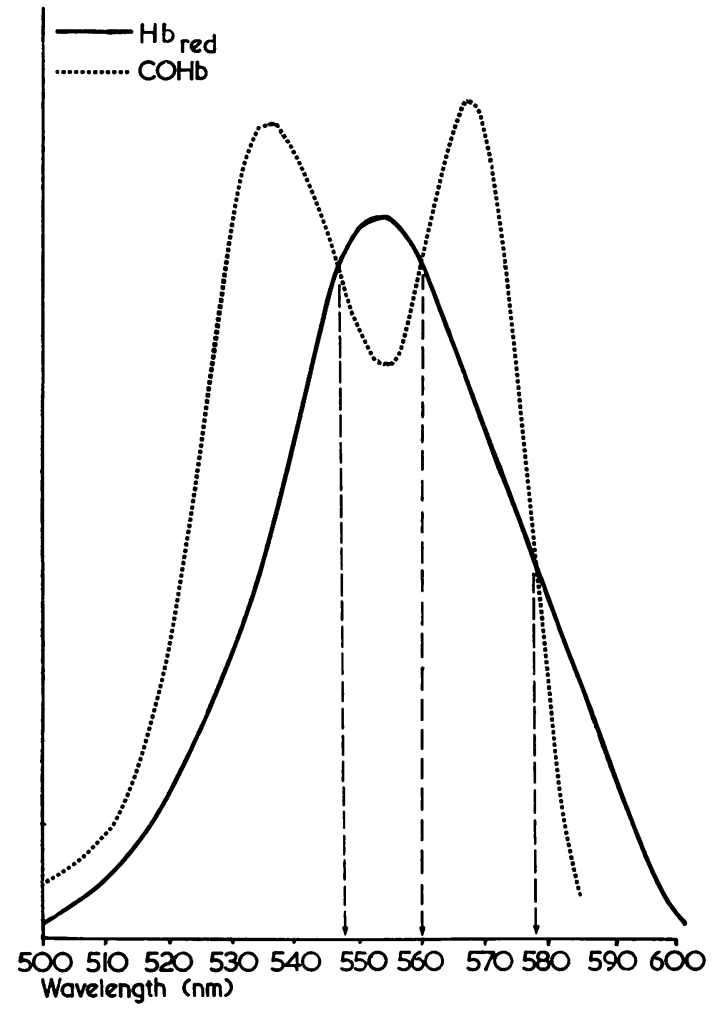

Fig. 1 Absorbance spectra of $\mathrm{Hb}_{\text {red }}$ and $\mathrm{COHb}$ between 600 and $500 \mathrm{~nm}$.

sample is obtained, proportional to the concentration of $\mathrm{COHb}$.

\section{CARBOXYHAEMOGLOBIN ESTIMATION}

To measure the $\mathrm{COHb}$ concentration in human or animal (dog, rat) blood the sample was collected into EDTA, and $100 \mu \mathrm{l}$ was diluted with $0.4 \%$ ammonium hydroxide to a final dilution of $1 / 100$. After thorough mixing, $5 \mathrm{ml}$ was transferred to a 6 $\mathrm{ml}$ plastic tube containing $50 \mathrm{mg}$ sodium dithionite to reduce the haemoglobin, and another $5 \mathrm{ml}$ was converted to $100 \% \mathrm{COHb}$ by passing carbon monoxide gas through the /solution for two minutes. Each tube was then capped and the blood well mixed. Readings were taken from these two samples on the spectrophotometer using the DVM. The plastic cuvettes containing the samples were read empty and then filled, to eliminate variations attributable to differences between cuvettes. Blood from control animals not exposed to carbon monoxide was examined alongside the test samples in an identical manner. From the results

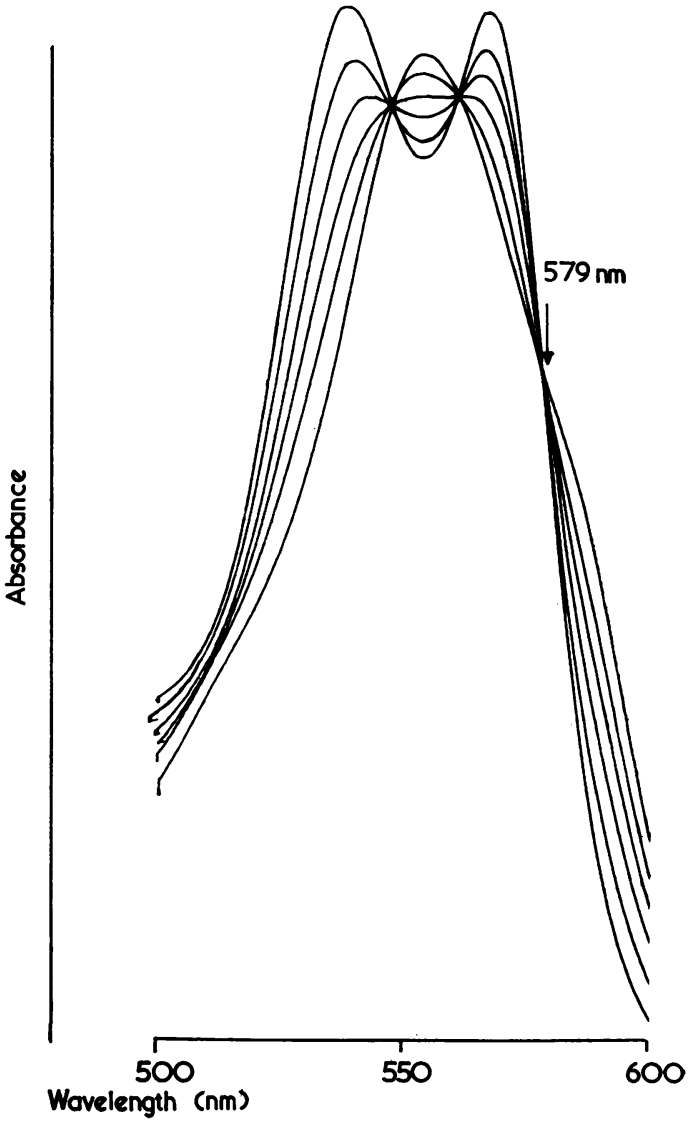

Fig. 2 Absorbance spectra of various concentrations of $\mathrm{COHb}$ between 600 and $500 \mathrm{~nm}$.

obtained with control and test samples the concentration of $\mathrm{COHb}$ was calculated, using the $0 \%$ and $100 \%$ samples.

\section{CALCULATION}

(In all cases the empty cuvette reading for the sample was subtracted from the filled cuvette reading on the DVM).

Test sample

$$
\begin{aligned}
100 \% \mathrm{COHb} & =\mathrm{A} \\
\text { Test result } & =\mathrm{B}
\end{aligned}
$$

Control sample

$$
100 \% \mathrm{COHb}=\mathrm{C}
$$$$
0 \% \mathrm{COHb}=\mathrm{D}
$$

$\% \mathrm{COHb}$ in test sample =

$$
\frac{B-\frac{A \times D}{C}}{A-\frac{A \times D}{C}} \times 100
$$




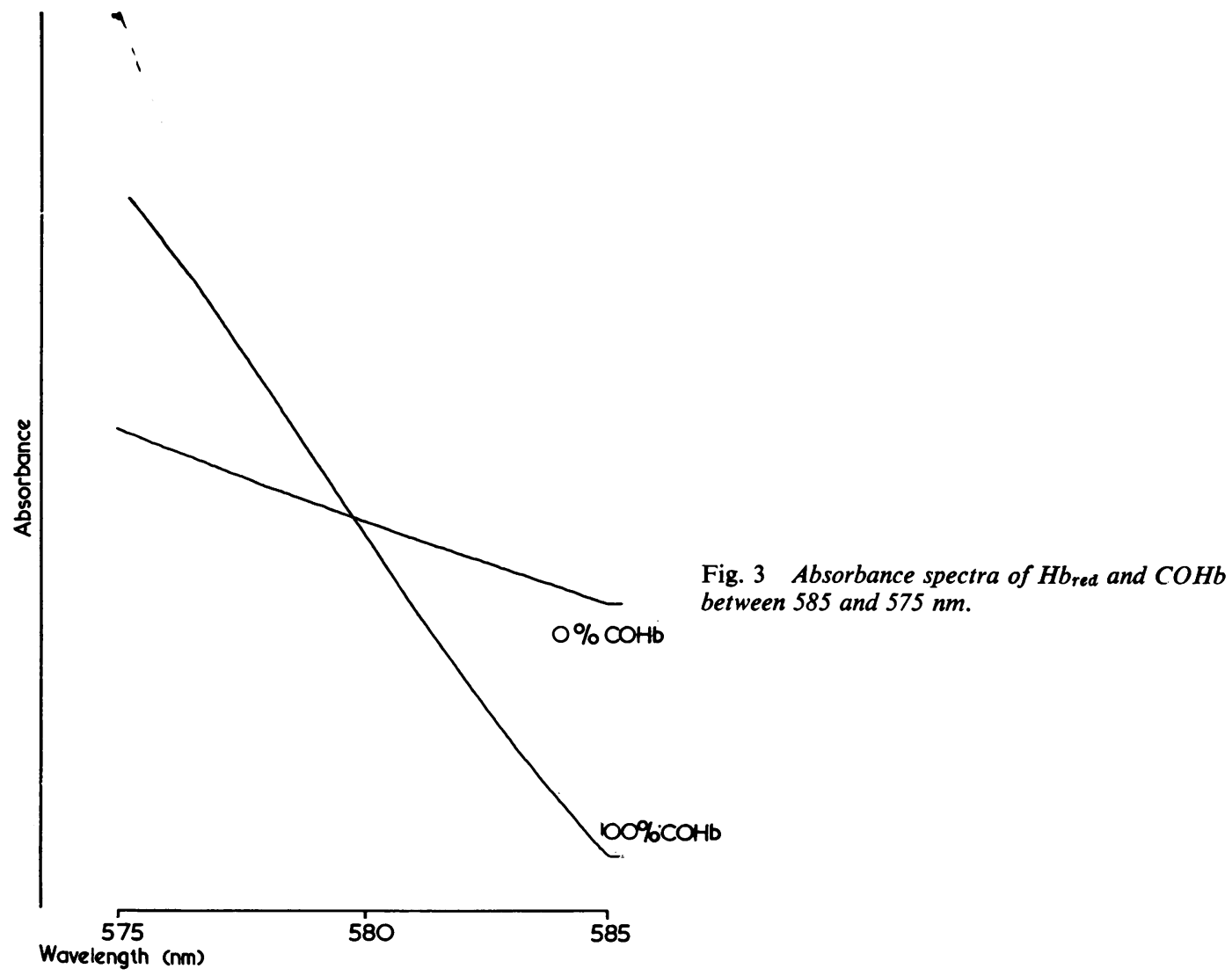

\section{Results}

\section{LINEARITY}

To verify that the concentration of $\mathrm{COHb}$ against the 1st derivative readings was linear, various concentrations were prepared. Using a sample of blood from an animal not known to have had contact with any source of carbon monoxide, a master dilution of blood was made. One half of this diluted sample was converted to $\mathrm{COHb}$ by bubbling carbon monoxide through the solution for 20 minutes followed by nitrogen gas for 30 minutes, to remove excess dissolved carbon monoxide, although this does cause some dissociation of the $\mathrm{COHb}$ (about $10 \%$ ). The remainder of the diluted sample had oxygen gas bubbled through it for 20 minutes to remove any $\mathrm{COHb}$, followed by nitrogen gas to remove excess dissolved oxygen. The oxygenated sample was then dispensed accurately in known quantities into sodium dithionite, the reducing agent. The $\mathrm{COHb}$ solution was then added accu- rately in small known amounts. These were well mixed before being read as above. Typical results can be seen in Figure 7 which shows concentrations of $\mathrm{COHb}$ between 0 and $93.6 \%$. The correlation between theoretical and observed values is excellent $(r=0.999)$. A similar experiment was carried out using samples of blood with a $\mathrm{COHb}$ concentration between $0 \%$ and $20 \%$ in $1 \%$ steps. The linearity of this was again excellent $(r=0.999)$.

\section{REPRODUCIBILITY}

Tests on reproducibility of the method between readings of the same subsamples, subsamples of the same dilution and dilutions of the same blood were carried out. The samples of blood used contained various concentrations of $\mathrm{COHb}$. The study was carried out with the wavelengths set both $3 \mathrm{~nm}$ apart and $1 \mathrm{~nm}$ apart.

\section{Reproducibility between readings}

Twenty samples of blood were each diluted $1 / 100$ 


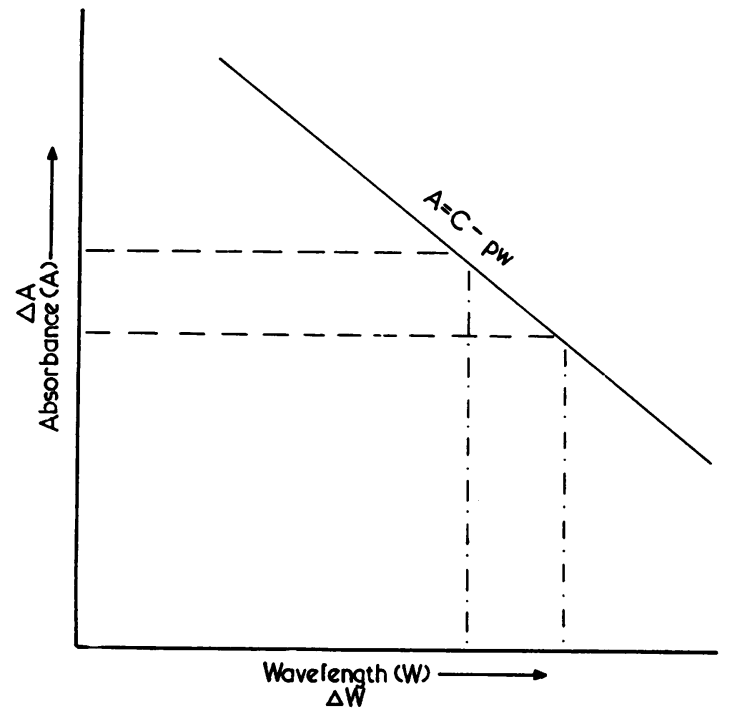

Fig. 4 Schematic absorbance curve of COHb.

with $0.4 \% \mathrm{w} / \mathrm{v}$ ammonium hydroxide to give a final volume of $10 \mathrm{ml}$. Each dilution was mixed thoroughly and half of each sample was placed in a $10 \mathrm{mg} / \mathrm{ml}$ solution of the reducing agent sodium dithionite. Carbon monoxide was bubbled through the remainder for two minutes. Each of these samples was then read four times consecutively in the 1st derivative mode, initially with wavelengths set $3 \mathrm{~nm}$ apart $\left(\lambda_{1_{579}}: \lambda_{2_{576}}\right)$, then with wavelengths set $1 \mathrm{~nm}$ apart $\left(\lambda_{1_{579}} ; \lambda_{2_{578}}\right)$. The results were analysed statistically and are shown in the Table.

\section{Reproducibility between subsamples}

Four samples of blood were each diluted 1/100 with $0.4 \% \mathrm{w} / \mathrm{v}$ ammonium hydroxide to give a final volume of $60 \mathrm{ml}$. Each dilution was mixed thoroughly and five portions of $10 \mathrm{ml}$ removed from each. After mixing, half of each $10 \mathrm{ml}$ sample was mixed with the reducing agent sodium dithionite and the remainder was gassed with carbon monoxide. Each of the 20 pairs of subsamples was read in random order in 1st derivative mode with the wavelengths set $3 \mathrm{~nm}$ apart. Statistical analysis of results is shown in the Table.

\section{Reproducibility between dilutions}

Two samples of blood were each diluted twenty times in the routine manner: $100 \mu l$ blood was mixed with $0.4 \% \mathrm{w} / \mathrm{v}$ ammonium hydroxide to give a final dilution of $1 / 100$. Each sample was well mixed, then $5 \mu \mathrm{l}$ was transferred into $50 \mathrm{mg}$ sodium dithionite; the remainder was gassed with carbon
Table Analysis of variance of results showing reproducibility between readings, subsamples and dilutions, at different wavelengths

\begin{tabular}{llll}
\hline & \multicolumn{3}{l}{ Wavelength } \\
Reproducibility & $\lambda 1579 \lambda^{2578}$ & $\lambda 1579$ & \multicolumn{2}{c}{$\lambda 2576$} \\
\hline Between readings & 0.2190 & 0.0563 \\
Between subsamples & - & 0.2319 \\
Between dilutions & & \\
$\quad 4 \cdot 161$ COHb (low) & - & 0.3351 \\
$13 \cdot 168$ COHb (high) & & 0.6006 \\
\hline
\end{tabular}

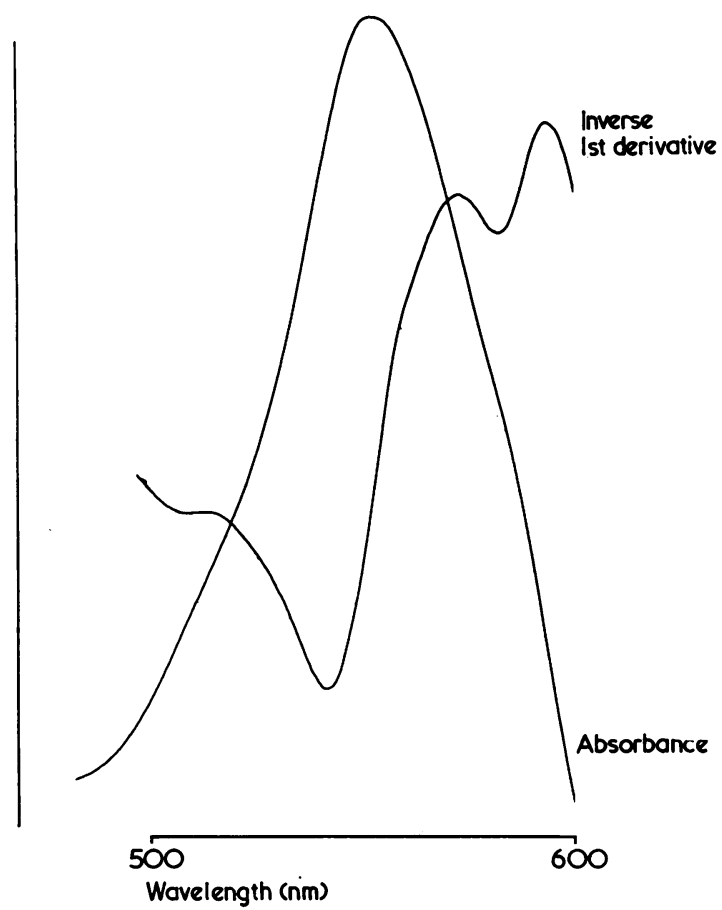

Fig. 5 Absorbance spectrum of $\mathrm{Hb}$ red between 600 and $500 \mathrm{~nm}$ with its inverse 1st derivative curve superimposed upon it.

monoxide for two minutes. Each of the 20 paired samples was read in random order in 1st derivative mode with wavelengths set $3 \mathrm{~nm}$ apart. Results were statistically analysed and are shown in the Table.

If only one dilution, one subsample and one reading are done on a blood sample using wavelengths $\lambda_{1_{579}}$ and $\lambda_{2_{576}} \mathrm{~nm}$ then in the worst possible case, the variance would be 0.33507 (SD $=0.05788$ ) for low $\mathrm{COHb}$ concentrations and 0.60064 (SD = 0.077501) for high $\mathrm{COHb}$ concentrations. If two dilutions per sample are done with one subsample and one reading then the variance is halved.

The variance attributable to machine reading is 


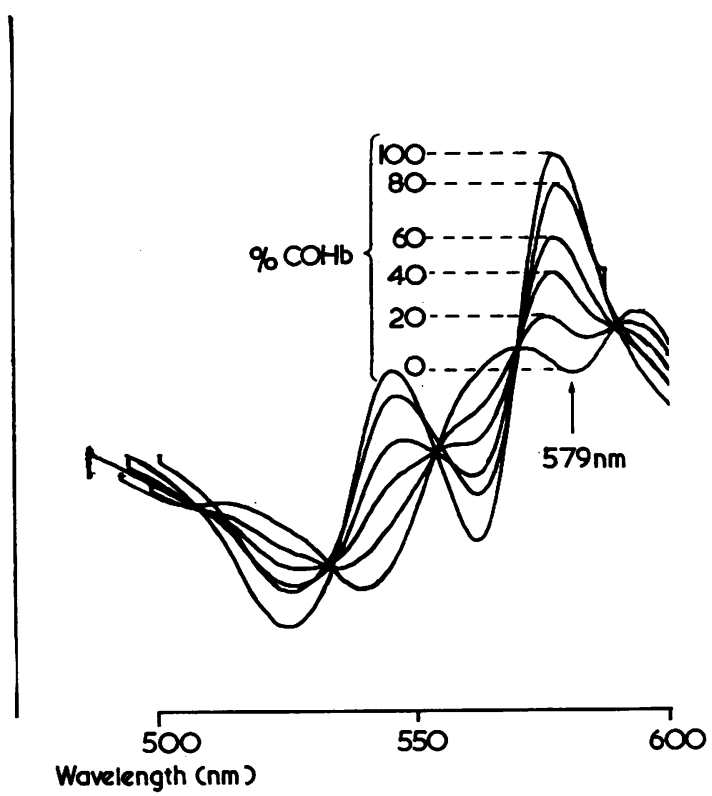

Fig. 6 Inverse 1st derivative spectra of various concentrations of $\mathrm{COHb}$ between 600 and $500 \mathrm{~nm}$.

that predicted by the necessity of making a decision as to the last digit on the DVM reading, when it tends to flicker between two figures, so this variance could be attributed solely to the electronic limitations of the output device.

Variance in the subsamples is due to sampling error which may, in part, be due to very slight differences in the amount of sodium dithionite used for reducing haemoglobin. Dilution error was not statistically significant.

There was no statistical evidence that the variances differed between the higher concentrations of $\mathrm{COHb}$ and the lower concentrations. This result was anticipated from the high correlation coefficient.

\section{Time}

Another aspect of the method was assessed, using the results from the above experiments. The deviation from the mean plotted against the order of reading the subsamples and dilutions gave a measure of the effect of time on the correlations. There was a time effect in that the readings of both reduced and $100 \%$ $\mathrm{COHb}$ showed a fall, whereas the calculated $\mathrm{COHb}$ concentration showed no such fall. This demonstrates that, during the two-hour period over which the experiment was carried out, the samples showed significant changes in $\mathrm{COHb}$.

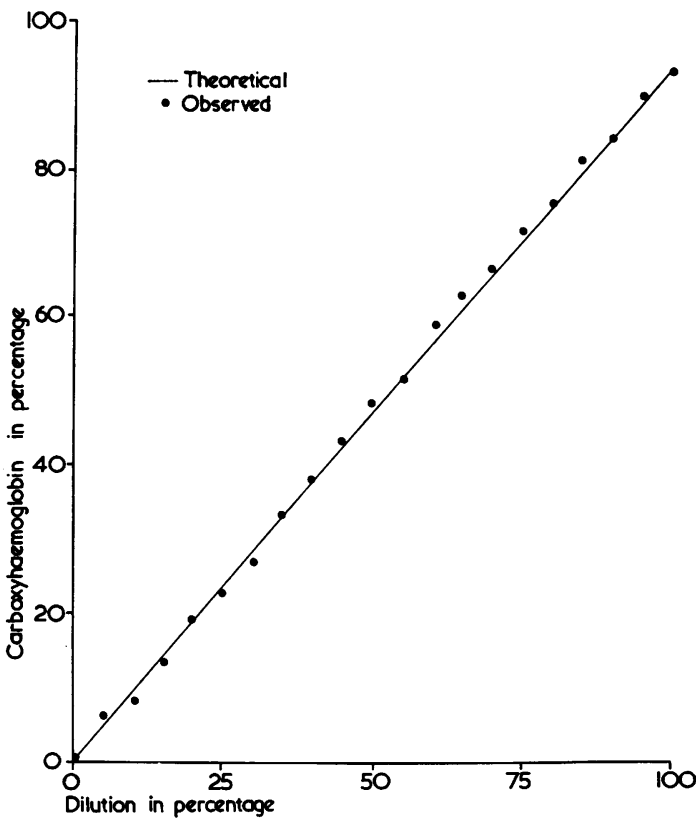

Fig. 7 Concentrations of $\mathrm{COHb}$ showing linearity between theoretical and observed values (correlation $r=0.999$ ).

\section{Discussion}

We believe the method described above is novel in that it employs digital read-out of a 1st derivative of an absorption curve. This combines the improved accuracy of a digital output with the sensitivity of 1st derivative recording. Although we have used this method for the measurement of carboxyhaemoglobin it is equally applicable to any mixture of two compounds with an isobestic point around which the slopes of both compounds are essentially even (in other words, 2nd derivative is zero).

The advantages of this method over those currently available are accuracy and speed. Our results show an accuracy of $\pm 0.5 \% \mathrm{COHb}$ over the whole range. The rapidity of the method is limited largely by the necessity to gas an aliquot of each sample with carbon monoxide, but a reasonable estimate for the output of two operators working together would be 150 samples during an ordinary working day.

The success of this method leads us to suggest that digital 1st derivative spectrophotometry may be an extremely useful tool in the estimation of carboxyhaemoglobin and possibly of other constituents of blood. Although the apparatus is rather expensive, it may already be found being used for other purposes in a number of laboratories. 
References

Blackmore, D. J. (1970). The determination of carbon monoxide in blood and tissue. Analyst, 95, 439-458.

Buchet, J. P., Lauwerys, R. R., and Roels, H. (1974). Comparison of three techniques for carboxyhaemoglobin determination. Archiv für Arbeitsmedizin, 4, 1-7.

Coburn, R. R., Danielson, G. K., Blakemore, W. S., and Forster, R. E. I. I. (1964). Carbon monoxide in blood: analytical method and sources of error. Journal of Applied Physiology, 19, 510-515.

Collinson, H. A., Rodkey, F. L., and O'Neal, J. D. (1968). Determination of carbon monoxide in blood by gas chromatography. Clinical Chemistry, 14, 163-171.

Grossman, C. A. (1966). Carbon monoxide: bibliography with abstracts. US Department of Health, Education and Welfare.

Klendsnoj, N. C., Feldstein, M., and Sprague, A. L. (1950). The spectrophotometric determination of carbon monoxide. Journal of Biological Chemistry, 182, 297-303.

Lambert, J. L., Tschorn, R. R., and Hamlin, P. A. (1972). Determination of carbon monoxide in blood. Analytical Chemistry, 144, 1529-1530.

Lily, R. E. C., Cole, P. V., and Hawkins, L. H. (1972). Spectrophotometric measurement of carboxyhaemoglobin. British Journal of Industrial Medicine, 29, 454-457.
Maas, A. H. J., Hamelink, M. L., and Leeuw, R. J. M. (1970). An evaluation of the spectrophotometric determination of $\mathrm{HbO}_{2}, \mathrm{HbCO}$ and $\mathrm{Hb}$ in blood with the $\mathrm{Co}$ oximeter I.1.182. Clinica Chimica Acta, 29, 303-309.

Paul, K. G., and Theorell, H. (1942). A colorimetrical carbon monoxide-haemoglobin method of determination for clinical use. Acta Physiologica Scandinavica, 4, 285-292.

Ramieri, A., Jr., Jatlow, P., and Seligsson, D. (1974). A new method for rapid determination of carboxyhaemoglobin by use of double wavelength spectrophotometry. Clinical Chemistry, 20, 278-281.

Rem, J., Siggaard-Anderson, O., Nørgaard-Pedersen, B., and Sørenson, S. (1972). Haemoglobin pigments, photometer for oxygen saturation, carboxyhaemoglobin and methaemoglobin in capillary blood. Clinioa Chimica Acta, 42, 101-108.

Siggaard-Anderson, O., Nørgaard-Pedersen, B., and Rem, J. (1972). Haemoglobin pigments, spectrophotometric determination of oxy-, carboxy-, met- and sulphaemoglobin in capillary blood. Clinica Chimica Acta, 42, 85-100.

Small, K. A., Radford, E. P., Frazier, J. M., Rodkey, F. L., and Collinson, H. A. (1971). A rapid method for simultaneous measurement of carboxy- and methaemoglobin in blood. Journal of Applied Physiology, 31, 154-160.

Stow, H. W., and Pelletier, H. F. (1967). Automated determination of blood carbon monoxide. Technicon Symposium on Automation in Analytical Chemistry, 4, 431-433.

\section{The November 1977 issue}

\section{THE NOVEMBER 1977 ISSUE CONTAINS THE FOLLOWING PAPERS}

Radiation-induced chromosome damage in human lymphocytes D. C. LLOYD AND G. W. DOLPHIN

Some ethical problems of hazardous substances in the working environment $\quad$ W. R. LEE

$200 \mathrm{kV}$ xeroradiography in occupational exposure to silica and asbestos R. GLYN THOMAS AND G. $\mathrm{K}$. SLUIS-CREMER

A mortality study of coke oven workers in two South Wales integrated steelworks G. M. DAVIES

Lead poisoning in a group of demolition workers B. C. CAMPBELl AND A. W. BAIRD

Measurement by gas chromatography of urinary hippuric acid and methylhippuric acid as indices of toluene and xylene exposure SHOHEI KIRA
Quantitative determination of hippuric and $\mathrm{m}$ methylhippuric acids in urine by high-speed liquid chromatography H. MATSUI, M. KASAO, AND $s$. IMAMURA

The neurotoxicity of toluene: EEG changes in rats exposed to various concentrations Y. TAKEUCHI AND N. HISANAGA

Book reviews

Notices

Information section

Index to volume 34

Copies are still available and may be obtained from the PUBLISHING MANAGER, BRITISH MEDICAL ASSOCIATION, TAVISTOCK SQUARE, LONDON, WC1H 9JR, price $£ 3.75$ (USA $\$ 9 \cdot 20$ ), including postage 